\section{One backyard at a time}

\section{Local action can curb habitat loss and counter global pessimism on biodiversity.}

$\mathrm{T}$ his month's global summit on biodiversity in Nagoya, Japan, is unlikely to draw the same level of attention as last year's climate talks in Copenhagen, but the problem it aims to address is as pressing, if not more so. From a global perspective, the news on biodiversity is bad, although at the local or national level, there is room for hope. So let's get the bad news out of the way. The Nagoya meeting, which aims to pursue the agendas of the international Convention on Biological Diversity, will document failures to show any real progress in sustainable consumption of biological resources, or to approach initial targets in conserving species and preserving habitats (see page 764). In some respects, even the basic terms of the convention have been opened up for renegotiation.

One example of why biodiversity matters is that about a dozen species make up around $80 \%$ of today's total global crop production. This is a lot of eggs in very few baskets. Maintaining biodiversity, especially among indigenous species, is crucial for the optimization of agricultural production across the range of climates and terrains. Witness the growing shift in African food production away from introduced crops such as barley and towards indigenous crops such as sorghum as countries pursue greater food security.

There are obvious parallels between the world's approaches to the biodiversity and climate problems. Both focus on global targets and the need for multilateral action to curb irreversible damage. Both are moving towards market solutions: funnelling cash from the developed world to poorer countries to preserve carbon and protect life. Biodiversity even has its own Stern Review of economic impacts. Led by banker Pavan Sukhdev, The Economics of Ecosystems and Biodiversity (TEEB) project, to be formally released in Nagoya, has valued the annual contribution to humankind of global flora and fauna at US\$5 trillion. 'Ecosystem services' is a clumsy term, but one that conservation scientists must get used to. Policy-makers and economists must in turn accept that the evidence they need to put a tradable price on biodiversity is currently as rare as some of the species they aim to save.

How can science help? Satellite monitoring is improving in coverage and resolution. But, too often, restrictions are placed on access to the resulting data, and policy-makers must address this. Satellites cannot do all of the work and people are needed on the ground to survey, monitor and count, particularly in developing countries. At a Science and Technology in Society forum on sustainability and biodiversity last week in Kyoto, Japan, there was clear concern about taxonomy's declining status. Although molecular biology can sample habitats for genetic diversity, and microbiology sheds light on microbial populations in habitats ranging from soil to our own guts, scientists are steadily losing the ability to map and understand life as most people experience it, at the organism level. For natural capital to be banked, that has got to change.

Unlike climate change, which probably needs a global framework for regional regulation of emissions to work, much national legislation to tackle biodiversity loss already exists. Stronger enforcement and stricter penalties would be a relatively easy win. Those politicians who have, rightly, talked up the threat of global warming should remember that the consequences for plants and animals are one of the climate impacts they seek to avoid. On current trends, how many threatened species will survive hunting, trapping and habitat destruction only to be wiped out by rising temperatures?

Biodiversity loss is best tackled locally, and here is the good news. From London's River Thames to Lake Biwa, Japan's largest freshwater lake, good management and a whole-system approach are restoring ecosystems and bringing benefits to local people. To build on such successes, scientists and policy-makers need to engage more seriously with those in the social sciences, who themselves must develop greater ambition to make a positive difference. Whether in Eritrea or the Amazon, convincing people to behave differently demands an understanding of indigenous populations' practical, cultural and spiritual relationships with their natural environment. The global picture is gloomy. But if each country can empower the citizens and international research communities that focus on local threats, using the tools of all the sciences, there could be movement rather than paralysis.

\section{Probe retires to a place in the Sun}

\section{A fitting end for the satellite that shed light on the age, shape and fabric of the Universe.}

$\mathrm{F}$ arewell, then, to NASA's Wilkinson Microwave Anisotropy Probe (WMAP): the little satellite that could. Last month, the spacecraft fired its boosters for the final time and fell into a graveyard orbit around the Sun, where it will remain as a permanent fixture in the Universe it helped to decode.

Launched in June 2001, the WMAP makes a strong case to be considered one of the greatest scientific experiments of all time. It turned cosmology from informed guesswork into a precision science, and brought our fuzzy understanding of the nature of the Universe into breathtaking focus. Along the way, its findings yielded some of the most highly cited papers in physics - as well as bewitching images that introduced millions of people to the truths and enduring mysteries of the cosmos.

The WMAP studied the remnants of heat that lingered after the Big Bang, a pattern frozen in time when the Universe was only about
380,000 years old and which has since stretched to microwave wavelengths. Subtle differences seen in the texture of this 'cosmic microwave background' by the WMAP have revealed the geometry, composition and age of the Universe. The probe showed that the Universe is flat and probably endless, and produced the first fine-resolution, full-sky map of the cosmic microwave background. It also revealed how this original light is polarized - the blueprint for the first galaxy formation. Physicists have yet to encounter dark matter or dark energy, but the WMAP has already audited the expected contribution of these components to the Universe: $23.3 \%$ and $72.1 \%$, respectively. And it has determined that ordinary matter makes up just $4.6 \%$ of the Universe, to within $0.1 \%$.

The probe's discoveries have resonated far beyond the scientific sphere. When singer-songwriter Katie Melua sang, "We are 12 billion light years from the edge/That's a guess/No one can ever say it's true" in her 2005 hit Nine Million Bicycles, science writer Simon Singh complained that the lyrics did not reflect current scientific knowledge. The WMAP, after all, had recently determined the age of the Universe with great accuracy. Melua agreed to re-record the song using Singh's revision: "We are 13.7 billion light years from the edge of the observable Universe/That's a good estimate with well-defined error bars/And with the available information." (See go.nature.com/ONJSQG.)

Science marches on, and a replacement for the WMAP is already in orbit: the European Space Agency's Planck satellite. Whatever this latest spacecraft may discover, the legacy of the Wilkinson Microwave Anisotropy Probe is assured. 